\title{
Debate
}

Gerontology

\section{Innovating Aging: Promises and Pitfalls on the Road to Life Extension}

\author{
Jan Vijg ${ }^{a}$ Aubrey D.N.J. de Grey ${ }^{b}$ \\ ${ }^{a}$ Department of Genetics, Albert Einstein College of Medicine, New York, N.Y., and ${ }^{b}$ SENS Research Foundation, \\ Mountain View, Calif., USA
}

\section{Key Words}

Technology · Life extension · Medical advances - Regulation · Preclinical research

\begin{abstract}
One of the main benefits of the dramatic technological progress over the last two centuries is the enormous increase in human life expectancy, which has now reached record highs. After conquering most childhood diseases and a fair fraction of the diseases that plague adulthood, medical technology is now mainly preoccupied by age-related disorders. Further progress is dependent on circumventing the traditional medical focus on individual diseases and instead targeting aging as a whole as the ultimate cause of the health problems that affect humankind at old age. In principle, a major effort to control the gradual accumulation of molecular and cellular damage - considered by many as the ultimate cause of intrinsic aging - may rapidly lead to interventions for regenerating aged and worn-out tissues and organs. While considered impossible by many, there really is no reason to reject this as scientifically implausible. However, as we posit, it is not only scientific progress that is currently a limiting factor, but societal factors that hinder and may ultimately prevent further progress in testing and adopting the many possible interventions to cure aging.

(c) 2014 S. Karger AG, Basel
\end{abstract}

\begin{tabular}{ll}
\hline KARGER & $\begin{array}{l}\text { ( 2014 S. Karger AG, Basel } \\
\text { 0304-324X/14/0604-0373\$39.50/0 Openger }\end{array}$ \\
E-Mail karger@karger.com & $\begin{array}{l}\text { This is an Open Access article licensed under the terms of the } \\
\text { www.karger.com/ger }\end{array}$ \\
$\begin{array}{l}\text { Creative Commons Attribution-NonCommercial 3.0 Un- } \\
\text { ported license (CC BY-NC) (www.karger.com/OA-license), } \\
\text { applicable to the online version of the article only. Distribu- } \\
\text { tion permitted for non-commercial purposes only. }\end{array}$
\end{tabular}

\section{Introduction}

The world as we know it began at the turn of the 18th century with the industrial revolution in Britain. Since then, great inventions, such as the steam engine, electricity, radio and telephone, the automobile, airplane and the computer have been responsible for an enormous increase in economic growth. Economic growth increased wealth, first mostly for Europeans and Americans and now also for large numbers of people everywhere else on the globe. If one wishes to single out the most important of the accomplishments of this astonishing episode in human civilization, then that should surely be the dramatic increase in human life expectancy (fig. 1). Indeed, while only two centuries ago life expectancy at birth was no more than a few decades, a Japanese girl born today can expect to live to 83 , the highest life expectancy ever recorded for Homo sapiens. Most of this is the result of technological progress.

Food security, emerging in 18th century Europe due to improved agricultural technology, was the main driver of the increase in life expectancy over the last 200 years. Shortly thereafter, technological developments addressed the need for clean water and sanitation, suppressing ma-

\footnotetext{
Jan Vijg, PhD

Department of Genetics, Albert Einstein College of Medicine 1301 Morris Park Ave, Bronx, NY 10461 (USA)

E-Mail jan.vijg@einstein.yu.edu
}

Aubrey D.N.J. de Grey, PhD

SENS Research Foundation

110 Pioneer Way, Suite J

Mountain View, CA 94041 (USA)

E-Mail Aubrey@sens.org 

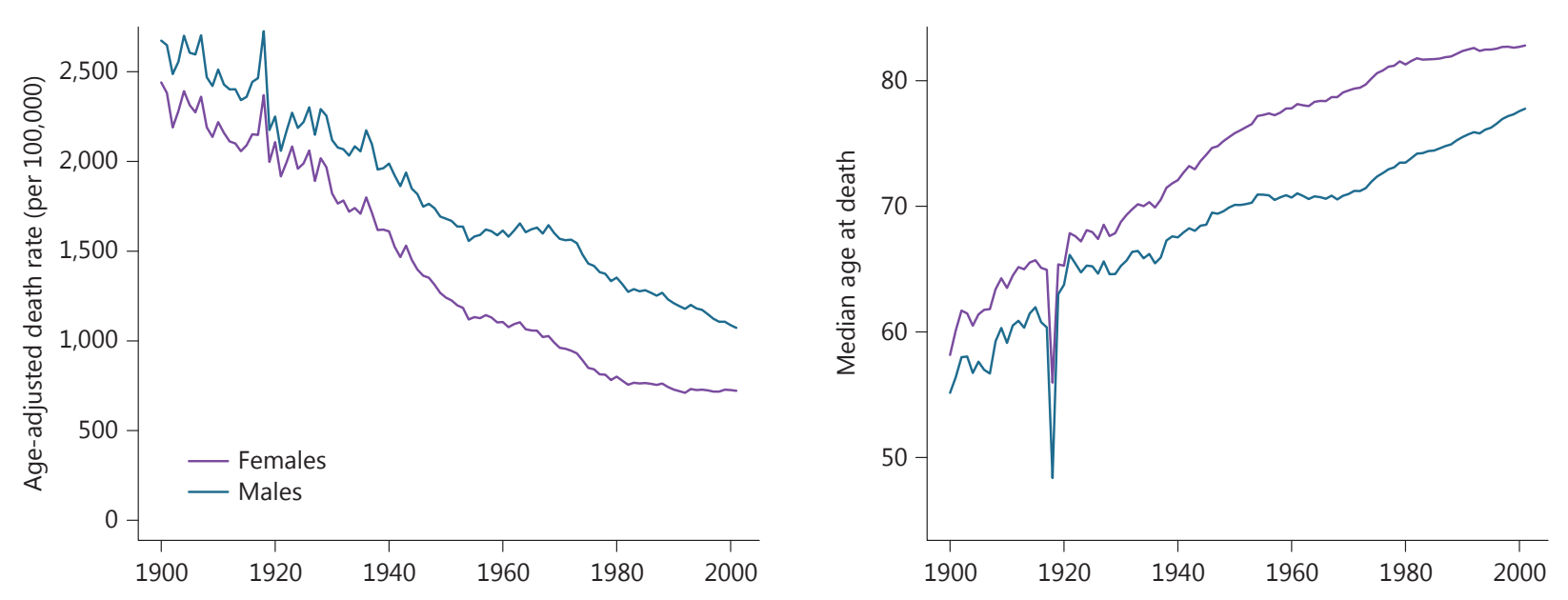

Fig. 1. As in other developed nations, in the USA, death rates (left) have fallen increasingly fast for both sexes, although very recently there has been no further decline for women. Simultaneously, median age at death (right) has increased dramatically, but now ap- pears to level off. Source: F.C. Bell, M.L. Miller: Actuarial study No. 120. Life tables for the United States social Security area 19002100. www.ssa.gov/OACT/NOTES/as120/LifeTables_Body.html.
Table 1. Some technological and non-technological milestones in life extension

\section{Technology-driven \\ Food security \\ Indoor plumbing, water purification, sanitation \\ Vaccination, disinfectants, antibiotics \\ Anesthesia, body imaging \\ Assistive devices (cane, walker, wheelchair) \\ Cancer chemotherapy, NSAIDs, COX-2 inhibitors \\ Joint replacement surgery}

\section{Non-technology-driven}

Shifts away from manual labor

Reduced violence

Behavioral changes (exercise, dietary change, decline in cigarette smoking)

Increasing education jor killer diseases, such as typhus and cholera. Later still, vaccination, disinfectants and antibiotics, all part of the broad palette of medical technology, greatly reduced infectious diseases as a cause of death. While initially confined to the developed world, more recently there has also been enormous progress in developing countries, especially Asia, but now also various parts of Africa and the Middle East (http://www.un.org/esa/population/publications/longrange2/WorldPop2300final.pdf).
The continuing reduction in mortality over the last few decades among the elderly is probably mostly due to nontechnological, preventative factors, such as a reduction in smoking, improved diets and exercise. However, medical interventions that prevent or attenuate disability in elderly, e.g., joint replacement therapy, NSAIDs, COX-2 inhibitors, blood pressure medications, play an ever important role. Progress at this level has mostly been limited to wealthy countries, and within those countries especially those with ample access to medical care, but now spreads rapidly all over the globe. Table 1 lists the main technological and non-technological pro-longevity factors thus far.

While mortality is now lower than it has ever been, life expectancy in the USA seems to have reached a plateau (fig. 1), raising the question if the major breakthroughs in medical technology are stalling. Somewhat paradoxically, there has been rapid progress in understanding aging and the control of life span over the last decades and the first successful pharmacological interventions to extend healthy life span in model organisms now indicate that aging is malleable. Here, we discuss our prospects of curing aging in the context of the many headwinds that may prevent the power of technology to significantly extend human health span, and break the winning streak of medical progress that has been seen in the past two centuries. 


\section{Rationale for Life Extension}

The first obstacle translational gerontology has to overcome is the serious doubt expressed by many, including some gerontologists themselves, that healthy life extension is possible or even desirable. Technology development with the explicit purpose of curing aging as we would cure a disease is essentially non-existent. A disease can be defined as a disorder or abnormality of structure or function. Aging cannot be abnormal because everyone suffers from it. Hence, there is a reluctance to accept aging as the equivalent of a disease. While it is true that there are age changes not considered a disease, aging and disease significantly overlap, as is obvious from single gene mutations in multiple organisms that affect both aging and disease [1]. Indeed, aging and late-life diseases are so intertwined that it is inconceivable that one could be addressed without the other.

Curing aging is not scientifically implausible [2] and one of us has introduced the concept of 'longevity escape velocity', a ladder of progress where medical advances will delay aging-related degeneration and death to such an extent that there is time to seek more effective therapies later on [3]. The expectation is that these will come more and more quickly, but even if they only come at a steady rate they could still have the effect of ultimately preventing ill-health and death from old age.

Recently, in this journal, it was argued by Olshansky and Carnes [4] that 'Continuous maintenance and repair of our bodies that approaches perfection is a laudable goal, but achieving it requires technological fixes and a human biology that simply do not exist'. Indeed, while humans are ultimately nothing more than enormously complicated machines, the vagaries of evolution by natural selection created additional levels of stochastic complication that may be difficult to address. For example, a great many if not all genes providing a particular function have been co-opted for other purposes; resulting in adverse side effects of treatments targeting such genes. The selection processes that have molded an organism to function well into the age of first reproduction have also led to an explosion of unwanted by-products that become manifest only at old age. To correct what could be a virtually infinite set of pro-aging mechanisms might well be unresolvable [2].

What is seldom noted is that most if not all of the above reasoning applies equally well to age-related disease. Diseases such as cancer and diabetes are extremely complex and may well be incurable according to the exact same argument used by Olshansky and Carnes. Curing all dis-

Innovating Aging: Promises and Pitfalls on the Road to Life Extension eases and then die from aging is an unlikely proposition in view of the complex interactions among various diseases and between diseases and the aging process itself. A more likely scenario is that certain early-onset forms of these diseases will be cured, at least to some extent. Eventually, however, if healthy life span is not continuously increasing, medical research has come to an end. Based on this reasoning, we feel there is a strong rationale to develop interventions that prevent, halt or reverse aging and its disease sequelae, a position that is now increasingly shared among scientists active in the field of aging. Indeed, there is increasing evidence that interventions in aging rather than combating individual diseases will have beneficial effects on society as a whole $[5,6]$ and we will not dwell on these aspects here. In the next section we will describe the potential of science and technology to cure aging and the specific headwinds that make this a formidable challenge.

\section{Strategies for Comprehensively Postponing Age-Related III-Health}

The diseases of old age, being intrinsic side effects of the body's normal operation, are inherently impossible to eliminate in the way that we can realistically seek to do for infectious diseases or many early-onset chronic diseases. Here we need to take into account a possible biological basis for the age-related increase in incidence and severity of such diseases. A logical explanation is that they are caused by the initially asymptomatic accumulation of changes to the body's composition and structure - changes that are initially asymptomatic because the body is built to tolerate a certain quantity of them, but which thereafter exceed this tolerance and drive the emergence and progression of ill-health. The inherent imperfectness of living systems drives the accumulation of these changes, often considered as damage, which would be in keeping with the age-related decline in force of natural selection, according to most evolutionary biologists the ultimate reason for why we age [7]. Maintaining somatic tissues far beyond the period of first reproduction has no selective advantage [8].

One of the more obvious features of aging is the large variation in healthy life span among individuals of the same species. This is best documented for humans, in which case it is unmistakable that individuals living longer and healthier life spans do so predominantly not by virtue of a greater ability to withstand ill-health, but by staving off that ill-health [9]. This is, of course, entirely 
consistent with the damage-accumulation logic outlined above. For over a century, this has led some biologists to speculate on the possibility of 'tuning' metabolism so as to diminish the rate at which the aforementioned asymptomatic 'damage' accumulates. The feasibility of such a quest received a huge boost early last century, when McCay et al. [10] established that dietary restriction could postpone the ill-health and death of rodents by as much as $30-40 \%$. This result has been repeated many times and comparable success has been achieved with genetic and, more recently, pharmacological interventions that mimic, in part, the dietary restriction effect [11].

If aging is caused by damage accumulation, one might reasonably ask if it would not be possible to intervene directly at that level. In this respect, one of us has proposed to intervene in damage accumulation through damage repair therapies [12]. This approach offers the advantage that it is focused not on slowing the body's creation of molecular and cellular damage, but on repairing that damage after the fact, thereby delaying the point where the damage reaches pathogenic levels. Such interventions can be applied repeatedly, thereby in principle maintaining a sub-pathogenic damage load indefinitely.

Unfortunately, repairing somatic damage is very difficult. Indeed, as of yet, we do not have anything close to a comprehensive inventory of all the possible types of errors that can adversely affect health. Nevertheless, since accumulated damage is likely to be the root cause of aging, any approach to directly intervene at that level is a rational one and progress is being made at various levels. For example, cell loss can in principle be counteracted by using stem cells, and tumor cells can be eliminated by targeted therapy [13], immunotherapy and combinations thereof [14]. New strategies of removing senescent cells are on the horizon [15] and the same is true for catabolic enhancement to improve lysosomal function [16], immunotherapeutic approaches against protein aggregates [17] and even allotypic expression of mitochondrial genes to circumvent mitochondrial mutation accumulation [18].

Hence, major scientific advances in understanding and manipulating aging, at least in model organisms, strongly suggest that increasing human life span is a realistic goal. However, before this can be taken a step further by beginning to vigorously pursue a program aimed at testing in humans those interventions that were shown successful in animals, multiple obstacles need to be overcome. It will be necessary to greatly expand development of interventions in model organisms - most importantly the mouse - and study their phenotypic consequences other than life span. Such studies are expensive since even rodents have long life spans. Hence, short-term models are needed that effectively mimic age-related pathophysiological conditions at much earlier age. Mouse models showing premature aging due to a genetic defect in DNA repair could fill this gap [19]. Since life span studies on humans are not feasible, subsequent translation of these findings to humans requires surrogate markers demonstrating efficacy in delaying or preventing particular agerelated phenotypes [20]. While formidable, these obstacles - many of which inherent to studying aging in humans - can and will be overcome.

In principle, then, practical strategies for slowing aging down and eventually halting or even reversing it would then follow automatically as antibiotics followed the germ theory of disease. Or would they? Most investors are familiar with the phrase 'Past performance is no guarantee of future results'. Like the stock market, technology development has also known its ups and downs. In world history, periods featuring major bursts of innovation have alternated with long periods of stasis and there is evidence that our current society has also entered an era of technological deceleration [21]. This has consequences also for anti-aging medicine and it is to this third and most formidable barrier in the war on aging that we now turn.

\section{Societal Pitfalls and Constraints in Healthy Life Extension}

Technology differs from science in the sense that whereas science is interested in acquiring new knowledge about the natural world, technology involves the products and processes to control that natural world [21]. While nowadays it is taken for granted that science and technology are two sides of the same coin, the great inventors who laid the foundations of our current post-industrial world were usually not trained at universities and did not immediately make the link between their work and science [21]. Ideally, practical innovation would be driven by the seamless integration of science and technology. The power of harnessing basic science in the development of new technology is best illustrated by the explosion of innovative new products from the 1940s onwards by both private and government labs. In rapid succession, industrial laboratories like Bell Labs (e.g. transistor, mobile phone), RCA Labs (e.g. color television, liquid crystal displays), Xerox's PARC (e.g. graphical user interface, ethernet) and government laboratories like the Depart- 
ment of Defense (e.g. internet, GPS) and NASA's Jet Propulsion Laboratory (e.g. image processing and cleanroom technology) transformed the world. While many of these inventions directly or indirectly contributed to modern medicine, medical technology on its own shared significantly in this bounty by developing antibiotics, the kidney dialysis machine, cancer chemotherapeutic drugs, vaccines against polio, measles and many other devastating diseases, birth control pills, and statins to name only a few [22].

All these accomplishments were the fruits of a unique combination of unfettered, basic science and product development, basic science with a purpose one could say. Unfortunately, this seamless connection between basic and applied research has been broken, with the famous laboratories from the past pursuing short-term commercial targets and/or are starved of funding [21, 23]. While usually government is blamed for stifling innovation by excessive regulation, industry is equally guilty of the current innovation shortfall by trying to avoid every possible risk with ever more sophisticated business models that dictate slight changes in existing products rather than embarking on dramatically novel approaches. This is certainly true in medical research and it is safe to say that irrespective of the great scientific accomplishments sketched above, agelessness is not the inevitable outcome of our quest to cure all diseases and aging as well, not even for a species like ours that over the past eons has demonstrated conclusively that it is capable of things generally held to be impossible. In the medical industry, excessive government regulation and conservative business models go hand in hand.

For example, most of the costs involved in bringing a new therapy to patients come not from the initial discovery research but from clinical testing and regulatory submission. Development of new medicines is a for-profit activity and increased risk, therefore, provides a very strong incentive to be conservative. Sometimes drugs are withdrawn from the market because of one or two serious adverse events out of tens of thousands of patients. This happened with the arthritis pain killer, Vioxx, withdrawn from the market by Merck in 2004 because a new study had found a higher rate of heart attacks and strokes in patients taking the drug than in those on a placebo. However, the vast majority of arthritis patients benefit from this kind of drug, all of which have been linked to cardiovascular risks [24]. There are many examples of quick market withdrawal of promising new medication based on economic considerations of threatening massive legal and regulatory action.

Innovating Aging: Promises and Pitfalls on the Road to Life Extension



Fig. 2. New drug approvals by the US FDA versus R\&D expenditures from 1963 to 2008 [from 26].

For developing pro-longevity interventions, the regulatory bar is much higher. The Food and Drug Administration (FDA) currently does not even recognize anti-aging medicine and clinical trials (using biomarkers as end point) are therefore not useful. Moreover, startlingly often, clinical trials deliberately exclude the elderly [25], not only undermining geriatricians efforts at providing treatment, but of course also greatly reducing the chances that a cure for aging, or for that matter the very age-related diseases the clinical trials are often aimed at, will ever emerge.

While increased regulation reflects how careful we have all become in protecting each other from mishap, adverse effects - even fatalities - among subjects of clinical trials cannot be entirely prevented and are part of the process of innovation. Under the current climate, highly promising treatments find themselves subject to much longer development times or even cancellation at the slightest sign of trouble. It is important to understand that reduced tolerance for mishap, either personal or financial, underlies this entrenchment of society and industry alike. Many of the great biomedical inventions of yore, including likely such mainstays of current medicine as kidney dialysis and chemotherapy, could never be developed in current societies.

As expected, the rate of approval of new drugs by the FDA is slowing down even while research expenditures have steeply risen (fig. 2) [26]. The average cost to develop a drug has now risen from about USD 100 million a few decades ago to USD 1.3 billion (in today's dollars), with most of this phenomenal increase due to phase III 
Fig. 3. NIH funding from fiscal 1994 to fiscal 2012. The dashed line and asterisks show the addition of ARRA funds in fiscal 2009 and 2010. Source: J.A. Johnson, P.W. Smith: The National Institutes of Health (NIH): Organization, funding, and congressional Issues. Congressional research Service 7-5700 (www.crs.gov; R41705).

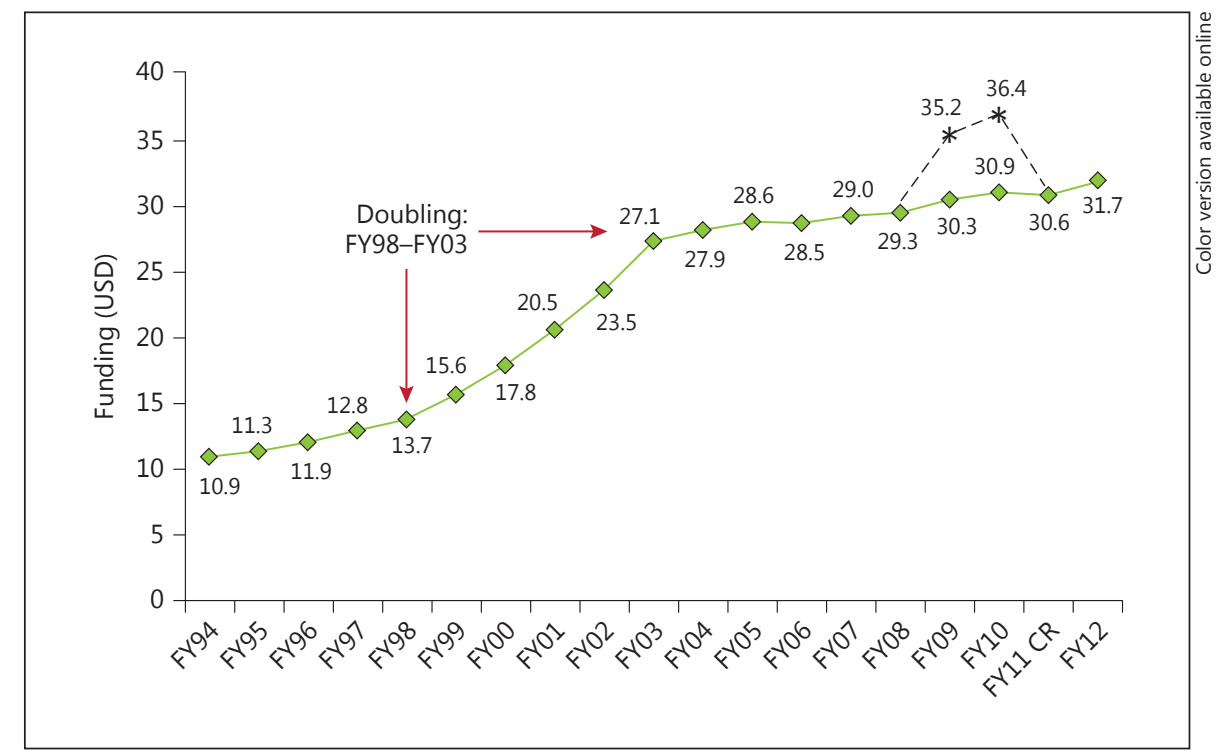

clinical trials [27]. It is simply too expensive to produce a novel therapy, which is always a risky proposition. The greatly increased costs drive non-sponsored clinical trials out of existence and incentivizes the drug industry to retrench and limit itself to slight modifications of existing drugs, trying to extend patent protection and hang on to branded drugs longer, for example, by making deals with generic drug makers. In turn, this leads to more and more treatments that offer very little advantage over older ones. A recent study of 315 clinical trials comparing a drug to a placebo showed that 1980s drugs were on average 7 -fold better than the placebo; by the 2000s this was reduced to less than 2-fold [28]. If anything, this has provided work for statisticians to prove that there is actually any positive effect of a new treatment at all! It has now become very difficult to bring the many basic discoveries for cures to fruition by translating them into revolutionary therapeutics. Because curing aging relies on major medical breakthroughs this is not good news for those of us who want to see geroscience blossom.

One notable casualty of increased regulation is the almost complete abandonment of the research field by physicians. No longer as was common in the past are they actively involved in new research that once gave us antibiotics, cancer chemotherapy, hypertension drugs and statins. Regulation has now become so exhaustive that even doctors who do want to spend time on testing new therapies are no longer able to do so. Nowadays, extensive protocols must be prepared for the institutional review board and most doctors are unable to do all that. Ironi- cally, those who manage to still get involved in research prefer to help unraveling the complex molecular pathways that play a role in disease processes rather than expose themselves to the less rewarding practical work that may actually lead to something that helps their patients. In other words, the clinical innovators of the past responsible for much of the spectacular progress of medicine are now withdrawing from the field [29]. This situation is obviously not black and white. A gigantic research machine, operating in a dense fog of regulations, still produces results and occasionally a life-saving treatment.

The often heard explanation for the recent, slow progress in medical technology (and other technologies) is the enormity of the problems, requiring much more research. With the current budget crises in Europe and the USA, many scientists rang alarm bells arguing that any cuts in their research budgets would greatly endanger the development of new treatments for human disease. Unfortunately, a further continuing expansion of research budgets may not bring successful treatments any closer. Indeed, there is no evidence that the doubling of funding for the US National Institutes of Health from 1998 to 2003 (fig. 3) had a major effect on health outcomes. The problem is not only funding, but the organization of the research.

First, there is the trend towards big, top-down science projects at the expense of investigator-driven, basic research grants. As we have seen, the big success of research in the past has been the opportunity of individual, unfettered research to naturally flow into novel, exciting products. This has already become very difficult due to an ex- 
tremely conservative review system, which expects almost $100 \%$ certainty that the proposed research will be successful. If now also, like in industry and government laboratories, research is going to be dictated from the top down, innovation becomes exceedingly difficult. This is being made worse by a bloated bureaucracy. In many universities, administration has grown out of all proportions at the expense of scientists [30]. At the source of the US funding system for medical research, the NIH, the remarkable stage has now been reached that the NCI's Office of Communications and Education (OCE) spent USD 381.2 million between 2006 and 2012 on educational brochures and updates of databases [31].

The growing disconnect between individual investigators and the clinically applicable fruits of their effort is a major reason for the disappointing success rate in translating research into clinical success. Rather than developing treatments themselves based on basic research of their own choosing, investigators now rely on others to do that for them. They have an incentive to publish in high-profile scientific journals, not to prepare their work for subsequent clinical application. The rush to publish may explain that findings cannot always be reproduced. Indeed, as reported recently, of 53 'landmark' publications in top journals, and from reputable laboratories, critical findings in 47 could not be replicated [32]. This may be due, at least in part, to different standards of conducting research. While preclinical studies and human clinical trials have different objectives (e.g. defining disease mechanisms and drug targets versus demonstrating clinical efficacy), the fundamental requirements for generating reliable and unbiased data should be similar, and thus standards of conduct and reporting should also be similar. For example, it should go without saying that also investigators involved in preclinical work should run their experiments in a blinded manner, i.e. with those who perform assessments unaware of the identity of the samples they process. Results should also be replicated a sufficient number of times and the practice of simply adopting the set of results that best conforms to expectations should be abandoned. While these examples of good laboratory practice seem to be self-evident, experience indicates that flawed research conduct is quite frequent.

\section{Conclusions and Future Prospects}

The desire to make us live longer and, most importantly, live healthier has been supported by some enormous collaborative research endeavors of which research- ers in the past could only have dreamt. We know all our genes, can visualize their activity in different parts of an organ and have tools to replace defective genes by healthy copies. However, we do not seem to be able to reap the fruits of all this progress because of increased difficulty to see new technology practically applied. In medicine, research and clinical practice have become different worlds, allowing only occasional foraging in each other's territories. The crushing load of regulations, often disproportionate to the actual risks, and an already highly sophisticated system for preventing and treating disease, which creates reluctance of both patients and doctors to expose themselves to the unavoidable problems that are always associated with testing new, potentially revolutionary treatments, make it difficult to develop and implement biomedical advances in clinical practice. How does this affect our chances to witness healthy life extension this century?

As one of us has argued elsewhere [21], many of the problems that currently constrain innovation are not the signs of failure, but instead the signs of a successful society. Indeed, life expectancy has not only improved in the rich world but also in underdeveloped areas on the globe. The human condition is improving everywhere, with mortality declining and fertility rates decreasing. Illiteracy rates have fallen dramatically and there are fewer and fewer children without primary education. World poverty is on the decline and the number of internet connections is increasing dramatically, offering previously unheard of opportunities for people in all parts of the world. This is due to the same factors that are responsible for reducing innovation. Regulatory constraints may slow down innovation, but contributed greatly in making the world a safer place. And although the advanced business models that effectively seek the highest profit at the lowest possible risk may leave no room for interventions that stop aging, they do provide a wealth of products at low cost. Indeed, governments and industry have matured and are not inclined to make major investments in something truly new and, therefore, risky. The question for us that remains is if under these conditions it will still be possible to inspire the necessary bursts of innovation for promoting healthy life extension.

One way to possibly accomplish that would be through a network of research-health, geriatric clinics in which basic research would be practiced literally at the bedside. Very much along the lines of the once so successful government and industry laboratories, such as Bell Labs, independent investigators would select the problems they will be working on, with their colleagues in an interdisci- 
plinary manner. Instead of academic criteria, such as publications in high-end journals, they should be evaluated solely on the basis of the clinically useful products delivered.

Obviously, such integrated research institutions will only be successful when they are able to quickly apply the novel treatments they develop, which is impossible under current conditions. For this reason it has been suggested to abandon phase III clinical trials, which is responsible for most of the costs of testing new treatments [27]. Treatments that have been found safe and promising should get approved for patients with all clinical data made public. Will such revolutionary change ever happen? Only time will tell.

\section{Acknowledgements}

The authors would like to thank the reviewers for their constructive comments and suggestions. We also thank Brent Calder for preparing figure 1 and Morgan Church for figures 2 and 3. The authors are supported by the NIH, the Glenn Foundation and the SENS Foundation.

\section{References}

$\nabla_{1}$ Kenyon C: The plasticity of aging: insights 12 De Grey AD, Ames BN, Andersen JK, Bartke from long-lived mutants. Cell 2005;120:449460.

2 Vijg J, Campisi J: Puzzles, promises and a cure for ageing. Nature 2008;454:1065-1071.

3 De Grey ADNJ: Escape velocity: why the prospect of extreme human life extension matters now. PLoS Biol 2004;2:e187.

4 Olshansky SJ, Carnes BA: Zeno's paradox of immortality. Gerontology 2013;59:85-92.

5 Rae MJ, Butler RN, Campisi J, de Grey AD, Finch CE, Gough M, Martin GM, Vijg J, Perrott KM, Logan BJ: The demographic and biomedical case for late-life interventions in aging. Sci Transl Med 2010;2:40 cm21.

6 Goldman DP, Cutler D, Rowe JW, Michaud PC, Sullivan J, Peneva D, Olshansky SJ: Substantial health and economic returns from delayed aging may warrant a new focus for medical research. Health Aff (Millwood) 2013;32: 1698-1705.

7 Gladyshev VN: The origin of aging: imperfectness-driven non-random damage defines the aging process and control of lifespan. Trends Genet 2013;29:506-512.

8 Kirkwood TB: Understanding the odd science of aging. Cell 2005;120:437-447.

9 Atzmon G, Schechter C, Greiner W, Davidson D, Rennert G, Barzilai N: Clinical phenotype of families with longevity. J Am Geriatr Soc 2004;52:274-277.

10 McCay CM, Crowell MF, Maynard LA: The effect of retarded growth upon the length of life span and upon the ultimate body size. J Nutr 1935;10:63-79.

11 Kaeberlein M: Resveratrol and rapamycin: are they anti-aging drugs? Bioessays 2010;32:9699.
A, Campisi J, Heward CB, McCarter RJ, Stock G: Time to talk SENS: critiquing the immutability of human aging. Ann NY Acad Sci 2002; 959:452-462; discussion 463-455.

13 Haber DA, Gray NS, Baselga J: The evolving war on cancer. Cell 2011;145:19-24.

14 Quispe-Tintaya W, Chandra D, Jahangir A, Harris M, Casadevall A, Dadachova E, Gravekamp C: Nontoxic radioactive Listeria(at) is a highly effective therapy against metastatic pancreatic cancer. Proc Natl Acad Sci USA 2013;110:8668-8673.

15 Tchkonia T, Zhu Y, van Deursen J, Campisi J, Kirkland JL: Cellular senescence and the senescent secretory phenotype: therapeutic opportunities. J Clin Invest 2013;123:966-972.

16 Mathieu JM, Wang F, Segatori L, Alvarez PJ: Increased resistance to oxysterol cytotoxicity in fibroblasts transfected with a lysosomally targeted Chromobacterium oxidase. Biotechnol Bioeng 2012;109:2409-2415.

17 Kerchner GA, Boxer AL: Bapineuzumab. Expert Opin Biol Ther 2010;10:1121-1130.

18 Wallace DC, Fan W, Procaccio V: Mitochondrial energetics and therapeutics. Annu Rev Pathol 2010;5:297-348.

19 Hoeijmakers JH: DNA damage, aging, and cancer. N Engl J Med 2009;361:1475-1485.

20 Swindell WR, Ensrud KE, Cawthon PM, Cauley JA, Cummings SR, Miller RA: Indicators of 'healthy aging' in older women (65-69 years of age). A data-mining approach based on prediction of long-term survival. BMC Geriatr 2010;10:55.
21 Vijg J: The American Technological Challenge: Stagnation and Decline in the 21st Century. New York, Algora Publishing, 2011.

- 22 Kirschner MW, Marincola E, Teisberg EO: The role of biomedical research in health care reform. Science 1994;266:49-51.

23 Gref LG: The Rise and Fall of American Technology. New York, Algora Publishing, 2010.

24 Gallagher RM: Balancing risks and benefits in pain medicine: wither Vioxx. Pain Med 2004; 5:329-330.

25 Zulman DM, Sussman JB, Chen X, Cigolle CT, Blaum CS, Hayward RA: Examining the evidence: a systematic review of the inclusion and analysis of older adults in randomized controlled trials. J Gen Intern Med 2011;26: 783-790.

26 Kaitin KI: Deconstructing the drug development process: the new face of innovation. Clin Pharmacol Ther 2010;87:356-361.

27 Roy ASA: Stifling new cures: the true cost of lengthy clinical drug trials; in Project FDA Report. New York, Manhattan Institute for Policy Research, 2012.

28 Olfson M, Marcus SC: Decline in placebocontrolled trial results suggests new directions for comparative effectiveness research. Health Aff (Millwood) 2013;32:1116-1125.

29 Mittra I: Why is modern medicine stuck in a rut? Perspect Biol Med 2009;52:500-517.

30 Ginsberg B: The Fall of the Faculty: The Rise of the All-Administrative University and Why It Matters. New York, Oxford University Press, 2011.

31 Editorial: Cancer costs. Nature 2013;495:142.

32 Begley CG, Ellis LM: Drug development: raise standards for preclinical cancer research. Nature 2012;483:531-533. 